\title{
Polymeric Scaffolds for Bone Tissue Engineering
}

\author{
Xiaohua Liv ${ }^{1}$ and Peter X. MA ${ }^{1,2,3}$ \\ ${ }^{1}$ Department of Biologic and Materials Sciences, University of Michigan, Ann Arbor, MI; ${ }^{2}$ Department of Biomedical Engineering, \\ University of Michigan, Ann Arbor, MI; and ${ }^{3}$ Macromolecular Science and Engineering Center, University of Michigan,
} Ann Arbor, MI, 48109-1078

(Received 30 June 2003; accepted 5 December 2003)

\begin{abstract}
Bone tissue engineering is a rapidly developing area. Engineering bone typically uses an artificial extracellular matrix (scaffold), osteoblasts or cells that can become osteoblasts, and regulating factors that promote cell attachment, differentiation, and mineralized bone formation. Among them, highly porous scaffolds play a critical role in cell seeding, proliferation, and new 3D-tissue formation. A variety of biodegradable polymer materials and scaffolding fabrication techniques for bone tissue engineering have been investigated over the past decade. This article reviews the polymer materials, scaffold design, and fabrication methods for bone tissue engineering. Advantages and limitations of these materials and methods are analyzed. Various architectural parameters of scaffolds important for bone tissue engineering (e.g. porosity, pore size, interconnectivity, and pore-wall microstructures) are discussed. Surface modification of scaffolds is also discussed based on the significant effect of surface chemistry on cells adhesion and function.
\end{abstract}

Keywords-Bone, Tissue engineering, Biodegradable, Polymer materials, Scaffolds.

\section{INTRODUCTION}

Bone tissue engineering offers a promising new approach for bone repair. ${ }^{50,67,96}$ Compared to traditional autograft and allograft procedures, bone tissue engineering techniques based on autogenous cell/tissue transplantation would eliminate problems of donor scarcity, supply limitation, and pathogen transfer and immune rejection. ${ }^{15,61}$ Therefore, it has become a rapidly expanding research area since the emergence of the concept of tissue engineering. ${ }^{3,19,29,60}$

Engineering bone typically uses an artificial extracellular matrix (or scaffold), osteoblasts or cells that can become osteoblasts, and regulating factors that promote cell recruitment, growth differentiation and mineralized bone tissue formation. Among them, highly porous scaffolds play a critical role in cell seeding, proliferation and new tissue formation in three dimensions (3D). ${ }^{63,64}$ The scaffold is

Address correspondence to Peter X. Ma, PhD, Department of Biologic and Materials Sciences, 1011 North University Avenue, Room 2209, University of Michigan, Ann Arbor, MI 48109-1078. Electronic mail: mapx@umich.edu a 3D substrate for cells, and serves as a template for tissue regeneration. Ideal scaffolds should be biocompatible, biodegradable, and promote cellular interactions and tissue development, and possess proper mechanical and physical properties. ${ }^{10,39,105}$

A variety of materials have been used for replacement and repair of damaged or traumatized bone tissues. ${ }^{34,49,57,92}$ These materials include metals, ceramics, polymers (natural and synthetic) and their combinations. Metals and ceramics have two major disadvantages for tissue engineering applications: they are lack of degradability in a biological environment, and their processability is very limited.$^{68} \mathrm{In}$ contrast, polymers have great design flexibility because the composition and structure can be tailored to the specific needs. They are therefore attractive candidates. Biodegradability can be imparted into polymers through molecular design. Some polymers contain chemical bonds that undergo hydrolysis upon exposure to the body's aqueous environment, and some others can degrade by cellular or enzymatic pathways. For these reasons, polymeric materials have received considerable attention and are widely studied for bone tissue engineering applications. ${ }^{13}$ This review will focus on the selection of polymeric materials, scaffold design, and fabrication techniques. Surface modification of scaffolds is also discussed considering the significant effect of surface chemistry on cells adhesion and function. Many other factors such as cell sources, regulating molecules and their delivery, mechanical stimulation, bioreactor design, in vitro and in vivo cultivation conditions, animal models, and clinical considerations are also critically important for successfully engineering bone and other mineralized tissues. However they are beyond the scope of this paper and will not be covered here.

\section{POLYMERIC MATERIALS}

The scaffolds for bone tissue engineering should be fabricated from a biocompatible polymer, which does not have the potential to elicit an immunological or foreign body reaction. The chosen polymer can degrade at a controlled rate in concert with tissue regeneration. The degradation 
products should not be toxic and must be easily excreted by metabolic pathways. Many types of polymeric materials have been used for bone tissue engineering. ${ }^{4,34,81}$ They can be simply categorized as naturally derived materials [e.g. collagen and fibrin) and synthetic polymers (e.g. poly(lactic acid) (PLA), poly(glycolic acid) (PGA), and their copolymers PLGA]. Naturally derived materials have the potential advantage of biological recognition that may positively support cell adhesion and function. However, they may exhibit immunogenicity and contains pathogenic impurities. There is also less control over their mechanical properties, biodegradability, and batch-to-batch consistency. Many of them are also limited in supply and can therefore be costly. An advantage of synthetic polymers is reproducible largescale production with controlled properties of strength, degradation rate and microstructure. Therefore, synthetic biodegradable polymers have been widely used as vehicles for cell transplantation and scaffolds for tissue engineering.

Collagen is a fibrous protein, and is a main component of extracellular matrix of mammalian tissues including bone, cartilage, tendon, ligament, skin and so on. , $27,43,86,98^{\text {About }}$ 25 types of collagen differing in their chemical composition and molecular structure have been identified so far while type I collagen is known to be the most abundant one of all. ${ }^{46}$ Mizuno et al. utilized type I collagen as the matrix of bone marrow stromal cells and found bone marrow stromal cells could differentiate into osteoblasts on type I collagen matrix in vivo, but type II, III, and V collagen did not possess this property. ${ }^{74}$ Their results implied that type I collagen matrix offers a suitable environment for the induction of osteoblastic differentiation in vitro and osteogenesis in vivo. Caplan's group investigated the possibility of using hyaluronic acid-based polymers as cell carriers for tissue-engineered repair of bone and cartilage. ${ }^{90}$ Their results indicated that the hyaluronic acid-based delivery vehicles are superior to porous calcium phosphate ceramic with respect to the amount of cells loaded per unit volume of implant. As mentioned above, there are several concerns over the use of natural polymers as scaffolds for bone tissue engineering. These include their weak mechanical strength to give sufficient structural support and protection for the seeded osteoblasts, and the risks of pathogen transmission and immunorejection associated with natural materials from animal and cadaver sources.

Poly $(\alpha$-hydroxy acids), including PGA, PLA, and their copolymer PLGA, are the most popular and widely used synthetic polymeric materials in bone tissue engineering. ${ }^{24,36,42,44,55,65,79}$ These polymers, having a long history of use as degradable surgical sutures, have gained FDA approval for certain human use and are reasonably biocompatible. The ester bonds in these polymers are hydrolytically labile, and these polymers degrade by nonenzymatic hydrolysis. The degradation products of PGA, PLA and PLGA are nontoxic, natural metabolites, and are eventually eliminated from the body in the form of carbon diox- ide and water. The degradation rates of these polymers can be tailored to satisfy the requirements from several weeks to several years by altering the chemical composition (e.g. the LA/GA ratio in the PLGA copolymers), crystallinity, molecular-weight, and molecular weight distribution. Although these polymers have already been widely used in bone tissue engineering research, there are ongoing research efforts in improving the functionality of these polymers to further expand their applications. Other polymers have also been investigated for bone regeneration such as polyanhydrides, ${ }^{32,41,95}$ polycarbonates, ${ }^{16,23}$ polyphosphazene, ${ }^{52}$ polyfumarates ${ }^{80,107}$ and poly(butylenes terephthalate)/poly(ethylene oxide). ${ }^{20}$

Synthetic degradable hydrogels are emerged as a way to deliver cells and serve as injectable scaffolds for tissue engineering. PEG-based hydrogel scaffolds have been developed for bone regeneration by several groups. . $^{12,31,59,73}$ The nonadhesive hydrogel was modified with adhesive RGD peptide to facilitate cell adhesion and spreading. Increased osteoblast attachment and spreading were observed at high RGD concentrations. ${ }^{12}$ Poly(propylene fumarateco-ethylene glycol) hydrogels with a covalently linked RGD peptides were also developed. ${ }^{8}$ The RGD concentration was found to regulate osteoblast migration. ${ }^{8}$ Poly(aldehyde guluronate) hydrogel was also used as a hydrogel for bone regeneration. ${ }^{53}$ In addition to collagen, other naturally derived polymers such as alginate and their modifications were also used as hydrogels for bone tissue engineering. ${ }^{2,45,48,88}$ These hydrogels can be injected into the body in a minimally invasive manner for cell and protein delivery. ${ }^{21,85}$ However, a disadvantage of hydrogels for bone tissue engineering application is their low mechanical strength, posing difficulties in handling.

Although various polymeric materials are available and have been investigated for bone tissue engineering, no single biodegradable polymer can meet all the requirements for bone tissue engineering scaffolds. Each polymer material has its own characteristic advantages and disadvantages. On the other hand, composite materials often show an excellent balance between strength and toughness and usually improved characteristics compared to their individual components. As a matter of fact, natural bone matrix is an organic/inorganic composite material of collagen and apatites. From this point of view, composite materials are better choices as bone tissue engineering scaffolds. ${ }^{35,110,111}$ It is well established that hydroxyapatite (HAP) mimics the natural bone mineral and has been found to possess good mechanical and osteoconductive properties. ${ }^{1,82,99}$ Marra et al. incorporated HAP granules into poly(caprolactone) and PLGA blends and revealed the formation of collagen $500 \mu \mathrm{m}$ into the scaffold. ${ }^{69}$ Mikos's group mixed HAP short fibers as a reinforcing material to create porous $\operatorname{poly}(\alpha-$ hydroxy ester)/HAP composites. ${ }^{94}$ The processing technique involves solvent casting and compression molding followed by particulate leaching. The compressive yield 
strength of low porosity composite foams increased with increasing HAP fiber content. However, high porosity composite foams, which are suitable for cell seeding, were not reinforced by the introduction of increasing quantities of HAP short fibers. Laurencin et al. blended PLGA and HAP in attempt to improve mechanical properties as well as increase the osteoconductivity of PLGA scaffolds. ${ }^{5,51}$ In a 21-day osteoblast culture on the PLGA/HAP composite matrix, the cell attachment, function, and mineral formation showed some promising features of the HAP-containing matrix. However, the porosity of the scaffold was quite low, which might not be ideal for long-term cell survival, proliferation, and tissue formation due to mass transport limitations. Our group developed highly porous biodegradable polymer/apatite composite scaffolds through a thermally induced phase separation technique. ${ }^{110}$ Porosity as high as $95 \%$ was achieved. The mechanical properties of the composite scaffolds were significantly improved over the pure polymer scaffolds. The compressive modulus reached the same range as trabecular bone. The in vitro experiments confirmed that the osteoblast survival and growth were significantly enhanced in the PLLA/HAP composite scaffolds compared to the plain PLLA scaffolds ${ }^{67}$ Bonespecific markers, such as osteocalcin and bone sialoprotein, were expressed more abundantly in the PLLA/HAP composite scaffolds than in the PLLA scaffolds. Furthermore, the new bone tissue formation was significantly enhanced and was quite uniformly distributed throughout the PLLA/HAP composite scaffolds in contrast to only surface layer growth in plain PLLA scaffolds. The results from these groups consistently suggest that the strategy of using composite scaffolds of biodegradable polymers and bone mineral-like inorganic compounds is a viable approach in bone tissue engineering.

\section{SCAFFOLD DESIGN AND FABRICATION}

Several requirements should be considered in the design of 3D scaffolds for bone tissue engineering. ${ }^{28,40,105}$ First of all, an ideal bone scaffold should have sufficient porosity to accommodate osteoblasts or osteoprogenitor cells, to support cell proliferation and differentiation, and to enhance bone tissue formation. High porosity (such as $\geq 90 \%$ ) is important for scaffolds for any tissue engineering applications, including bone ${ }^{67,97}$ High interconnectivities between pores are also desirable for uniform cell seeding and distribution, the diffusion of nutrients to and metabolites out from the cell/scaffold constructs. The scaffold should have adequate mechanical stability to provide a suitable environment for new bone tissue formation. The scaffold degradation rate must be tuned to match the rate of new bone tissue regeneration in order to maintain the structural integrity and to provide scaffolding cues for tissue formation. Furthermore, the scaffold should have suitable surface chemistry for bone cells adhesion and function.
A variety of processing technologies have been developed to fabricate porous 3D polymeric scaffolds for bone regeneration. These techniques mainly include solvent casting and particulate leaching, gas foaming, emulsion freezedrying, electrospinning, rapid prototyping, and thermally induced phase separation.

\section{Solvent-Casting and Particulate Leaching Technique}

Solvent casting and particulate leaching is a simple and most commonly used method for fabricating scaffolds for tissue engineering. ${ }^{64,72}$ This method involves mixing watersoluble salt (e.g. sodium chloride, sodium citrate) particles into a biodegradable polymer solution. The mixture is then cast into the mold of the desired shape. After the solvent is removed by evaporation or lyophilization, the salt particles are leached out to obtain a porous structure. This method has advantages of simple operation, adequate control of pore size and porosity by salt/polymer ratio and particle size of the added salt. Mikos et al. used this method to fabricate biodegradable polymer scaffolds to engineer trabecular bone. ${ }^{72,93}$ However, the pore shape is limited to the cubic crystal shape of the salt. The difficulty of removing soluble particles from the interior of a polymer matrix makes it hard to fabricate very thick $3 \mathrm{D}$ scaffolds. ${ }^{76} \mathrm{In}$ fact, most of the porous materials prepared by solvent casting and particulate leaching method are limited to thickness ranging from 0.5 to $2 \mathrm{~mm} .{ }^{56} \mathrm{In}$ addition, their limited interpore connectivity is disadvantageous for uniform cell seeding and tissue growth. Sikavitsas et al. broken PLGA/salt composite materials into small pieces and compression molded them into thicker samples and then dissolved the salt to generate needed scaffolds for bone tissue engineering studies in bioreactors. Nonetheless, cell growth and mineralization were limited to the outside of the scaffolds, which was attributed to limited internal nutrient transport conditions by the investigators. ${ }^{89}$

Our group developed a method to create biodegradable polymer scaffolds with spherical pore shape and wellcontrolled interpore connectivity. ${ }^{62}$ Paraffin spheres are chosen as pore-generating materials. The created new scaffolding has a homogeneous foam skeleton (Fig. 1). The control of porosity and the pore size can be achieved by changing the concentration of the polymer solution, the number of the casting steps, and the size of the paraffin spheres. The main advantage of this method is that it can ensure the creation of a totally interconnected pore network in the polymer scaffold, which is critical to uniform cell seeding, tissue ingrowth, and regeneration. In addition, the paraffin sphere assembly can be dissolved in some organic solvents but not water. Therefore, certain water-soluble polymers can be involved in fabricating such scaffolds. However, what is the ideal pore size and interpore connectivity of such scaffolds for bone tissue engineering is yet to be investigated. 


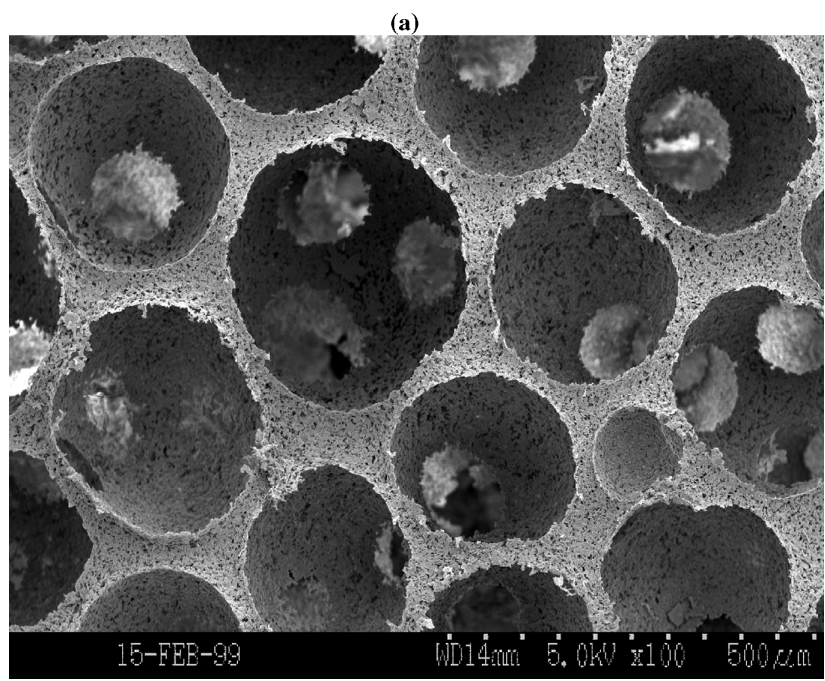

(b)

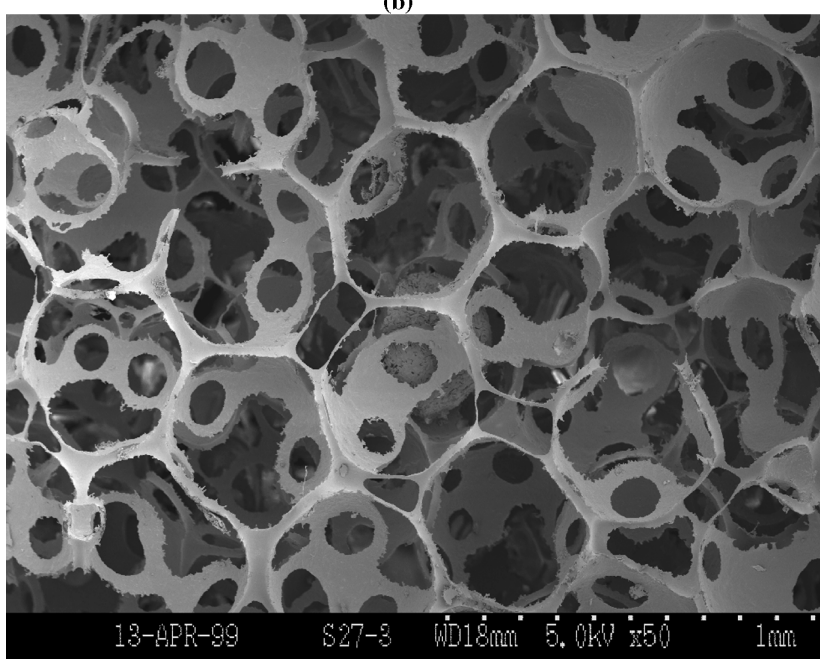

FIGURE 1. SEM micrographs of poly( $\alpha$-hydroxy acids) scaffolds. (a) PLLA foams prepared with paraffin spheres with a size range of 250-350 $\mu \mathrm{m}(\times 250)$. (b) PLGA foams prepared with paraffin spheres with a size range of $420-500 \mu \mathrm{m}(\times 50)$. (From Ma and Choi, ${ }^{62}$ copyright 2000 by Mary Ann Liebert, Inc. Reprinted with permission.)

\section{Gas-Foaming Process}

Gas foaming process can be used to fabricate highly porous polymer foams without the use of organic solvents. ${ }^{18,33,75}$ In this approach, carbon dioxide $\left(\mathrm{CO}_{2}\right)$ is usually used as an agent for the formation of polymer foam. Solid polymer disks are exposed to high pressure $\mathrm{CO}_{2}$ to allow saturation of $\mathrm{CO}_{2}$ in the polymer. Thermodynamic instability is then created by rapidly releasing $\mathrm{CO}_{2}$ gas from the polymer system, followed by the nucleation and growth of gas bubbles in the material. Polymer sponges with a pore size of $100 \mu \mathrm{m}$ and a porosity up to $93 \%$ can be fabricated using this technique. The disadvantage of this method is that it yields mostly a nonporous surface and closed-pore struc- ture, with only $10-30 \%$ of interconnected pores. ${ }^{33,75}$ The porosity and interpore connectivity can be significantly improved by combining particulate leaching technique with the gas-foaming process although completely eliminating closed pores remains challenging. ${ }^{33}$

\section{Emulsion Freeze Drying}

Emulsion freeze-drying technique was used for the fabrication of highly porous PLGA scaffolds. ${ }^{101,102}$ The processing method consists of creating an emulsion by homogenization of a polymer solution (in an organic solvent) and water mixture, rapidly cooling the emulsion to lock in the liquid state structure, and removing the solvent and water by freeze-drying. Scaffolds with porosity greater than $90 \%$ and a pore size ranging from 20 to $200 \mu \mathrm{m}$ can be fabricated with this method. ${ }^{101}$ One disadvantage of this technique is the closed pore structure in the resulting matrix. ${ }^{76}$

\section{Electrospinning Technique}

Electrospinning is a fabrication process that uses an electric field to control the formation and deposition of polymer fibers onto a target substrate. ${ }^{9,38,70,83,108}$ In electrospinning, a polymer solution or melt is injected with an electrical potential to create a charge imbalance. At a critical voltage, the charge imbalance begins to overcome the surface tension of the polymer solution to form an electrically charged jet. The jet within the electric field is directed toward the ground target, during which time the solvent evaporates and fibers are formed. This electrospinning technique can fabricate fibrous polymer scaffolds with fiber diameters ranging from several microns down to several hundred nanometers. ${ }^{54}$ The 3D scaffold shapes other than sheets or cylinders have not been demonstrated using this technique.

\section{Rapid-Prototyping Techniques}

Rapid prototyping is a technology based on the advanced development of computer science and manufacturing industry. ${ }^{106}$ The main advantage of these techniques is their ability to produce complex products rapidly from a computer-aided design (CAD) model. One of these rapid prototyping techniques, called 3D printing, was first developed at the Massachusetts Institute of Technology and has been used to process biodegradable polymer scaffolds for tissue engineering applications. ${ }^{26,84}$ This process generates components by ink-jet printing a binder on to sequential powder layers. The operation parameters such as the speed, flow rate, and drop position can be computer controlled to produce complex 3D polymer scaffolds. Biological agents, such as growth factors, can also be incorporated into the scaffolds in the printing process. However, the limitation of this method is that the resolution is determined by the jet size, which makes it difficult to design and fabricate scaffolds with fine microstructures. The porosity of the scaffold 
fabricated with this method is low, and the mechanical properties of the scaffolds have to be significantly improved. ${ }^{108}$

\section{Thermally Induced Phase Separation}

The controlled thermally induced phase separation process was first used for the preparation of porous polymer membranes. This technique was recently utilized to fabricate biodegradable 3D polymer scaffolds. ${ }^{109}$ In this approach, the polymer is first dissolved in a solvent at a high temperature, liquid-liquid or solid-liquid phase separation is induced by lowering the solution temperature. Subsequent removal of the solidified solvent-rich phase by sublimation leaves a porous polymer scaffold..$^{58,76,87,109}$ The pore morphology of the scaffolds varies depending on the polymer, solvent, concentration of the polymer solution and phase separation temperature. One advantage of this method is that the fabricated scaffolds often have good mechanical properties. For example, a PLLA scaffold fabricated using a solid-liquid phase separation technique has a modulus approximately 20 times higher than that of the scaffold fabricated using the well-documented salt-leaching technique from the same polymer and with the same porosity. ${ }^{67}$ However, this method usually generate scaffolds with a pore size of 10-100 $\mu \mathrm{m}$, which may not be ideal for osteoblastic cell seeding and bone tissue growth. Using a coarsening process in the later stage of thermally induced phase separation, macroporous scaffolds with a pore diameter greater than $100 \mu \mathrm{m}$ can be generated. ${ }^{76,100}$

By using a solid-liquid phase separation technique, our group fabricated biodegradable polymeric scaffolds with a parallel array of microtubules (Fig. 2) ${ }^{65}$ Phase separation was induced using a uniaxial temperature gradient to obtain the oriented microtubular scaffolds. The porosity, diameter of the microtubules, the tubular morphology and their orientation can be controlled by fabrication parameters such as polymer concentration, solvent type, and temperature gradient. The mechanical properties of these scaffolds are also anisotropic, similar to oriented tissues. The new microtubular architecture may serve as superior scaffolds for the engineering of a variety of tissues with fibrillar and tubular architectures.

Collagen is one of the main extracellular matrix components of bone tissue, and its nano-fibrous architecture has long been noticed to play a role in cell adhesion, growth and differentiated function in tissue cultures. ${ }^{22,30,47,91}$ To mimic the nanofibrous architecture, our group developed a novel liquid-liquid phase separation technique to create a 3D interconnected fibrous network with a fiber diameter ranging from 50 to $500 \mathrm{~nm}$ (Fig. 3). ${ }^{66}$ Typically, the nanoscale fibrous matrices were fabricated with five steps: polymer dissolution, phase separation and gelation, solvent extraction, freezing, and then freeze-drying under vacuum. The fiber network formation depends on the gelling temperature and the solvent of the polymer solution. This nanofibrous
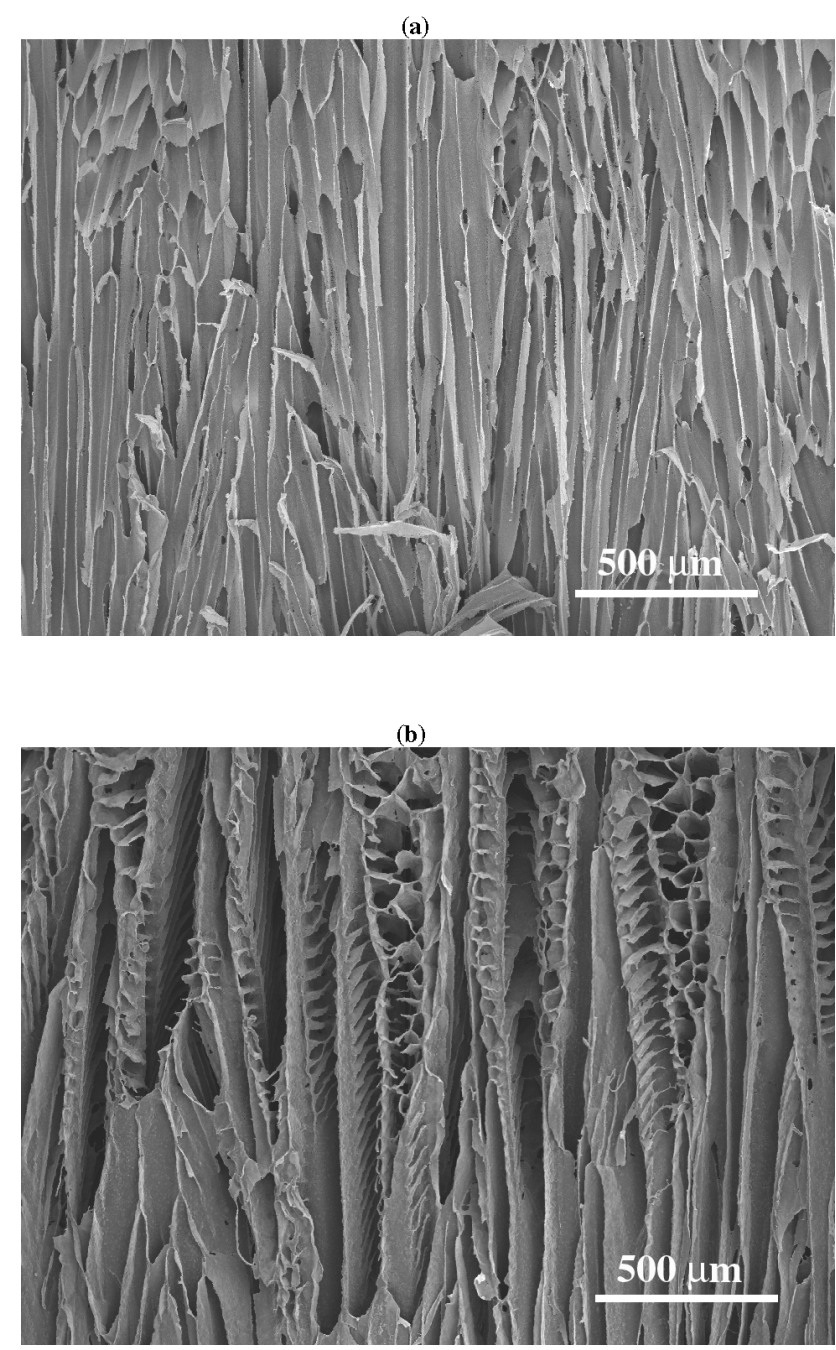

FIGURE 2. SEM micrographs of porous PLLA scaffolds prepared in benzene or dioxane solutions using a phaseseparation technique. (a) $2.5 \%$ (wt/v) PLLA/benzene, uniaxial temperature gradient, longitudinal section. (b) $5 \%(\mathrm{wt} / \mathrm{v})$ PLLA/dioxane, uniaxial temperaure gradient, longtitudinal section. (From Ma and Zhang, ${ }^{65}$ copyright 2001 by John Wiley \& Sons, Inc. Reprinted with permission.)

matrix has a much higher surface-to-volume ratio than those of fibrous nonwoven fabrics fabricated with the textile technology or foams fabricated with other techniques. When combined with the porogen leaching technique, synthetic polymer scaffolds are created with architectural features at several levels, including the anatomical shape (defined by a mold), macroporous elements (100 $\mu \mathrm{m}$ to millimeters), interfiber distance (microns), and the diameter of the fibers (50 to $500 \mathrm{~nm}$ ). ${ }^{103,112}$ These synthetic analogues of natural extracellular matrices combine the advantages of the synthetic biodegradable polymers and the nanoscale architecture similar to the natural extracellular matrix. They were found to selectively enhance protein adsorption and promote osteoblastic cell adhesion. ${ }^{103}$ 

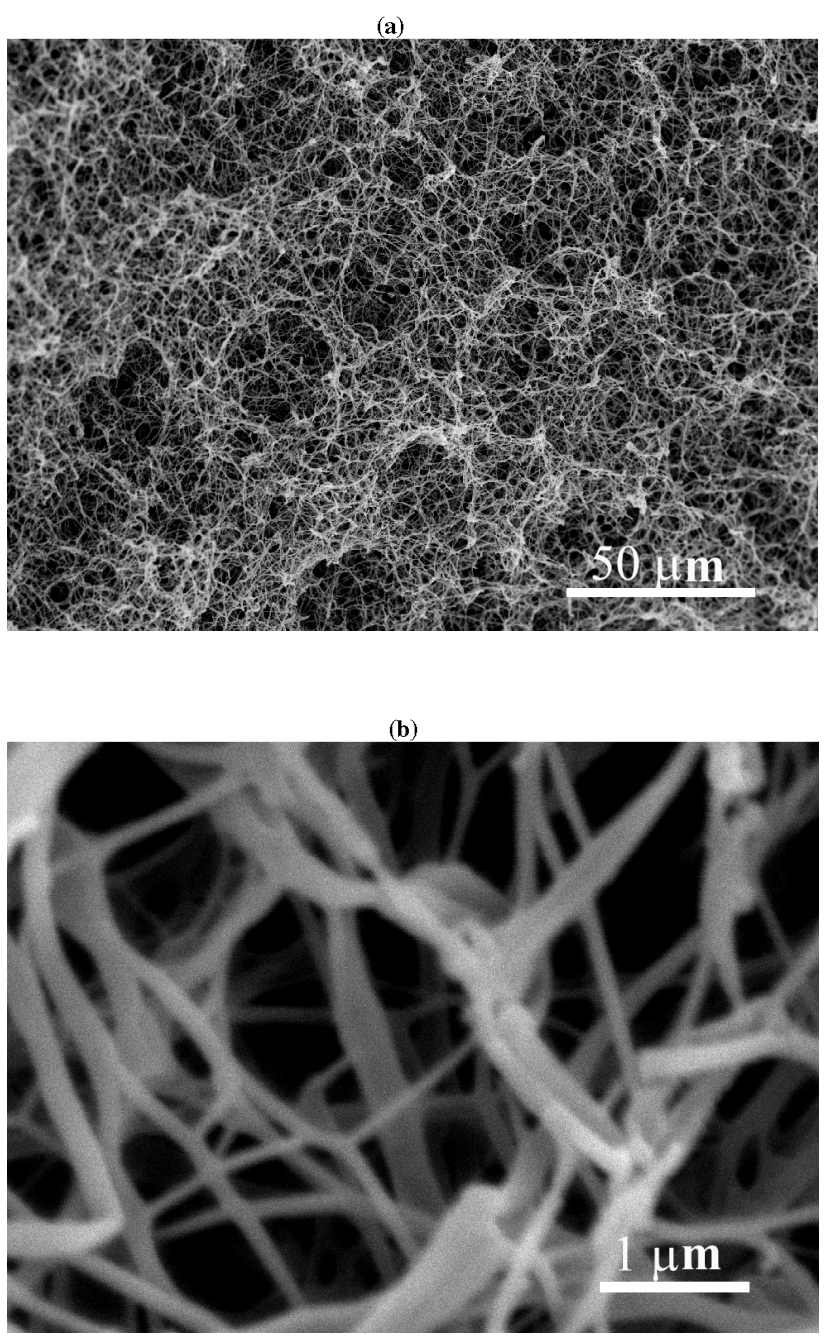

FIGURE 3. SEM micrographs of a PLLA fibrous matrix prepared from $2.5 \%(w t / v)$ PLLA/THF solution at a gelation temperature of $8^{\circ} \mathrm{C}$ : (a) $\times 50$; (b) $\times 20 \mathrm{~K}$. (From Ma and Zhang, ${ }^{66}$ copyright 1999 by John Wiley \& Sons, Inc. Reprinted with permission.)

\section{Surface Modification}

In tissue engineering, it is important to consider the interactions of cells with the scaffolding materials. The nature of the surface can directly affect cellular response, ultimately influencing the rate and quality of new tissue formation. Surface chemistry as well as surface topography determine whether protein molecules can adsorb and how cells attach and align themselves. ${ }^{11}$ Although a variety of synthetic biodegradable polymers have been used as tissue engineering scaffolding materials, one disadvantage of these scaffolds is their lack of biological recognition on the material surface. Hydrophobic polymers do not provide the ideal environment for cell-material interactions. ${ }^{71}$ Therefore, surface modification of polymeric scaffolds is an active research area. ${ }^{77,104}$

Gao et al. described a procedure for surface hydrolysis of PGA scaffold under strong alkaline condition to in- crease cell seeding density and improve biomaterial-cell interactions. ${ }^{25}$ Hydrolysis of ester bonds on the surface of PGA fibers changes the surface properties and results in higher seeding density and more spreading of cells as compared to unmodified PGA scaffolds. Cai et al. grafted chitosan on to poly(D,L-lactic acid) (PDLLA) by a coupling reaction on partially hydrolyzed PDLLA surface. The adhesion and proliferation of osteoblasts on modified PDLLA films were improved compared to the control PDLLA films. ${ }^{14}$ The limitation of this method is that it is technique sensitive and hydrolysis also alters the surface morphology and bulk mechanical properties.

Langer's group synthesized poly(L-lactic acid-co-Llysine) and chemically attached RGD peptide to the lysine residue of the copolymer. ${ }^{7,17}$ This approach combines the advantage of both natural and synthetic materials. The peptide content of the copolymer and their resulting chemical and physical characteristics could be varied in a controlled fashion by changing the molar ratio of the peptide to lysine units. These poly $(\alpha$-hydroxy acid)-based copolymers can be further modified by chemical attachment of a variety of biologically active molecules to meet the specific needs of biomedical and tissue engineering applications.

Plasma exposure is an effective procedure for surface etching. Nitschke et al. utilized low pressure ammonia plasma treatment for the modification of poly(3hydroxybutyrate) (PHB) thin films. ${ }^{78}$ The introduction of amine function was used for subsequent protein immobilization. The plasma treatment of PHB induced a durable conversion from a hydrophobic into a hydrophilic surface without significantly altering the morphology. Hollinger's group proposed a surface modification method using $\mathrm{NH}_{3}$ plasma treatment, followed by the attachment of poly(Llysine) and RGD peptide. ${ }^{37}$ The surface-modified polymer films enhanced osteoprogenitor cell attachment. Because of the limited plasma penetration, this method can only be used for two-dimensional (2D) films or very thin 3D structures.

As discussed earlier, most of the surface modification work this far has been focusing on 2D film surfaces or very thin 3D constructs. True 3D scaffolding surface modification is still a challenge. This is an area that has significant needs and potential for growth. Our group developed a biomimetic process that allows the in situ apatite formation on the internal surfaces of the pore walls of polymer scaffolds using simulated body fluids (SBF). ${ }^{111}$ A large number of microparticles with nano-featured flakeand needle-shaped bone-like apatites was grown on the internal surfaces of the porous polymer scaffolds (Fig. 4). The particle size and their coverage of pore surfaces can be controlled by the incubation conditions such as $\mathrm{SBF}$ concentration, incubation time, $\mathrm{pH}$ value, pretreatment using aqueous solution and so forth to achieve a desired surface modification pattern. In addition to the aimed surface chemical modification for improved osteoconductivity, the mechanical properties of the scaffolds 

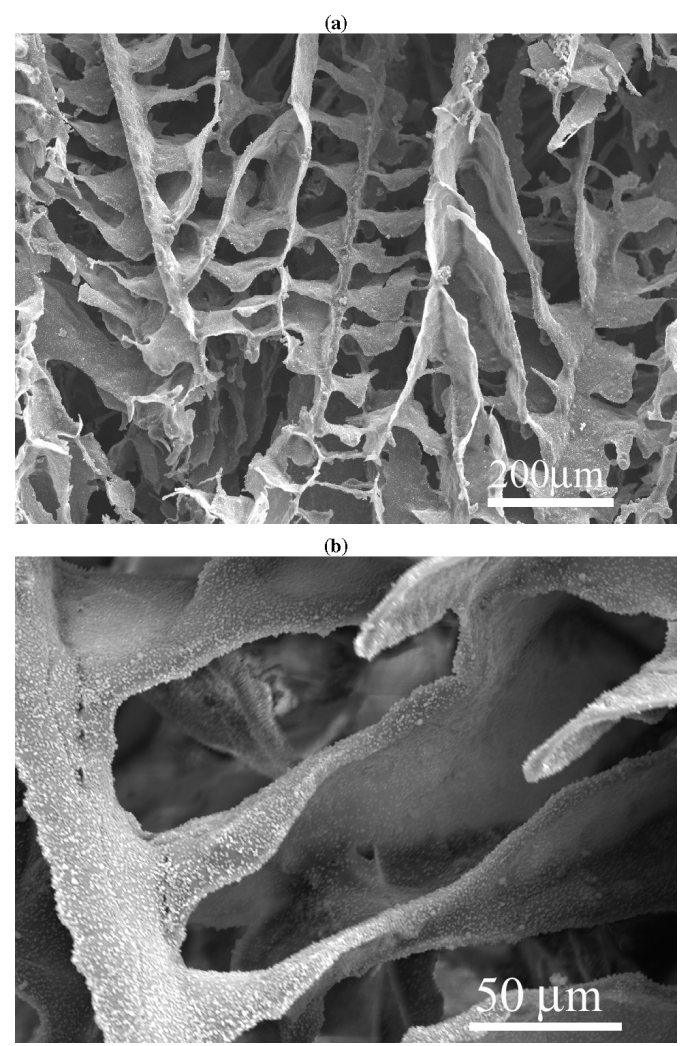

(c)
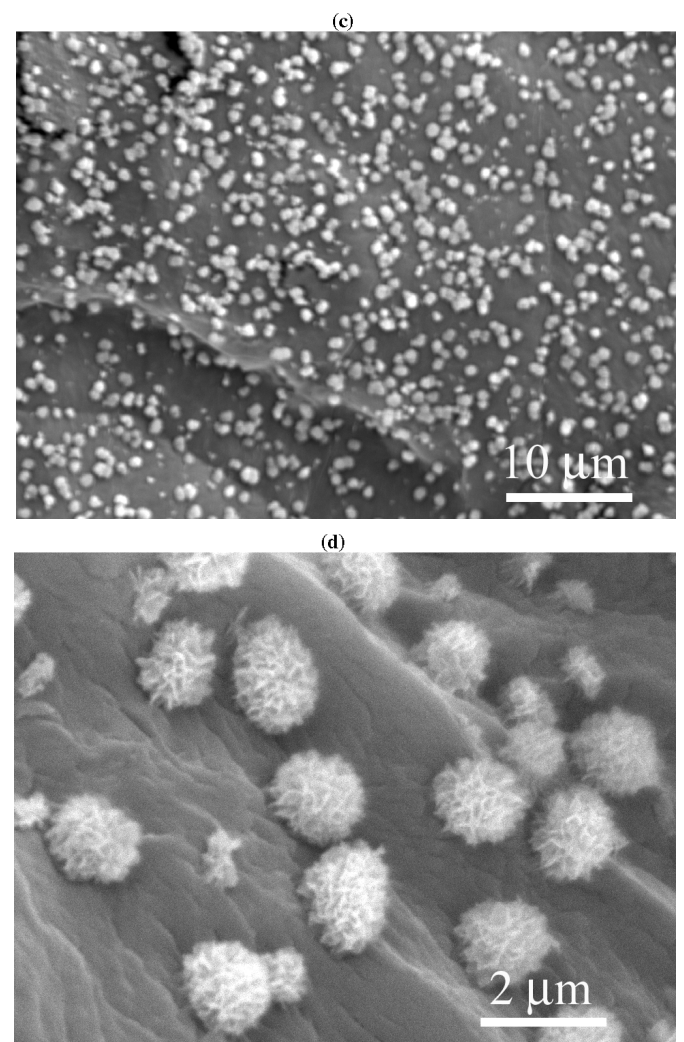

FIGURE 4. SEM micrographs of a PLLA scaffolds incubated in a simulated body fluid for $\mathbf{3 0}$ days: original magnifications (a) $\times 100$, (b) $\times 500$, (c) $\times 2000$, and (d) $\times 10,000$. (From Zhang and Ma, ${ }^{111}$ copyright 1999 by John Wiley \& Sons, Inc. Reprinted with permission.) were also significantly improved over the plain polymer scaffolds. ${ }^{11}$

\section{PERSPECTIVES}

The requirements of scaffolds for bone tissue engineering are complex. A variety of characteristic parameters, such as degradation rate, mechanical strength, porosity, pore size, pore microstructures, surface chemistry, and topography, should be carefully considered and controlled for the design and fabrication of scaffolds to meet the needs of a specific tissue engineering application. Although the ideal matrix materials and 3D scaffolds for bone tissue engineering have yet to be developed, much progress has been made during the last 10 years. The development, fabrication, and analysis of novel biodegradable polymeric biomaterials and scaffolds will still constitute a centerpiece of the research efforts in the field of bone tissue engineering. Using polymer scaffolding to controllably manipulate osteoblastic cell function is still in its infancy and expansion of this field will likely enable development of new therapies and technologies for bone tissue repair and regeneration.

\section{ACKNOWLEDGMENTS}

The authors acknowledge support from NIH/NIDCR (Grant Nos. DE 014755 and DE 015384: Peter X. Ma).

\section{REFERENCES}

${ }^{1}$ Akao, M., M. Sakatsume, H. Aoki, T. Takagi, and S. Sasaki. In-vitro mineralization in bovine tooth germ-cell cultured with sintered hydroxyapatite. J. Mater. Sci.-Mater. Med. 4:569-574, 1993.

${ }^{2}$ Alsberg, E., K. W. Anderson, A. Albeiruti, J. A. Rowley, and D. J. Mooney. Engineering growing tissues. Proc. Nat. Acad. Sci. U.S.A. 99:12025-12030, 2002.

${ }^{3}$ Athanasiou, K. A., C. M. Agrawal, F. A. Barber, and S. S. Burkhart. Orthopaedic applications for PLA-PGA biodegradable polymers. Arthroscopy 14:726-737, 1998.

${ }^{4}$ Athanasiou, K. A., G. G. Niederauer, and C. M. Agrawal. Sterilization, toxicity, biocompatibility and clinical applications of polylactic acid/polyglycolic acid copolymers. Biomaterials 17:93-102, 1996.

${ }^{5}$ Attawia, M. A., K. M. Herbert, and C. T. Laurencin. Osteoblastlike cell adherance and migration through 3-dimensional porous polymer matrices. Biochem. Biophys. Res. Commun. 213:639644, 1995.

${ }^{6}$ Badylak, S. F. Modification of Natural Polymers: Collagen. In: Methods of Tissue Engineering, edited by A. Atala, and R. P. Lanza. San Diego, CA: Academic Press, 2002, pp. 505-514.

${ }^{7}$ Barrera, D. A., E. Zylstra, P. T. Lansbury, and R. Langer. Copolymerization and degradation of poly(lactic acid colysine). Macromolecules 28:425-432, 1995.

${ }^{8}$ Behravesh, E., K. Zygourakis, and A. G. Mikos. Adhesion and migration of marrow-derived osteoblasts on injectable in situ crosslinkable poly(propylene fumarate-co-ethylene glycol)based hydrogels with a covalently linked RGDS peptide. J. Biomed. Mater. Res. Part A 65A:260-270, 2003. 
${ }^{9}$ Boland, E. D., G. E. Wnek, D. G. Simpson, K. J. Pawlowski, and G. L. Bowlin. Tailoring tissue engineering scaffolds using electrostatic processing techniques: A study of poly(glycolic acid) electrospinning. J. Macromol. Sci.-Pure Appl. Chem. 38:12311243,2001

${ }^{10}$ Bonadio, J., E. Smiley, P. Patil, and S. Goldstein. Localized, direct plasmid gene delivery in vivo: prolonged therapy results in reproducible tissue regeneration. Nat. Med. 5:753-759, 1999.

${ }^{11}$ Boyan, B. D., T. W. Hummert, D. D. Dean, and Z. Schwartz. Role of material surfaces in regulating bone and cartilage cell response. Biomaterials 17:137-146, 1996.

${ }^{12}$ Burdick, J. A., and K. S. Anseth. Photoencapsulation of osteoblasts in injectable RGD-modified PEG hydrogels for bone tissue engineering. Biomaterials 23:4315-4323, 2002.

${ }^{13}$ Burg, K. J. L., S. Porter, and J. F. Kellam. Biomaterial developments for bone tissue engineering. Biomaterials 21:2347-2359, 2000.

${ }^{14}$ Cai, K. Y., W. G. Liu, F. Li, K. D. Yao, Z. M. Yang, X. Q. Li, and H. Q. Xie. Modulation of osteoblast function using poly(D, L-lactic acid) surfaces modified with alkylation derivative of chitosan. J. Biomater. Sci.-Polym. Ed. 13:53-66, 2002.

${ }^{15}$ Chapekar, M. S. Tissue engineering: Challenges and opportunities. J. Biomed. Mater. Res. 53:617-620, 2000.

${ }^{16}$ Choueka, J., J. L. Charvet, K. J. Koval, H. Alexander, K. S. James, K. A. Hooper, and J. Kohn. Canine bone response to tyrosine-derived polycarbonates and poly(L-lactic acid). $J$. Biomed. Mater. Res. 31:35-41, 1996.

${ }^{17}$ Cook, A. D., J. S. Hrkach, N. N. Gao, I. M. Johnson, U. B. Pajvani, S. M. Cannizzaro, and R. Langer. Characterization and development of RGD-peptide-modified poly(lactic acidco-lysine) as an interactive, resorbable biomaterial. J. Biomed. Mater. Res. 35:513-523, 1997.

${ }^{18}$ Cooper, A. I. Polymer synthesis and processing using supercritical carbon dioxide. J. Mater. Chem. 10:207-234, 2000.

${ }^{19}$ Crane, G. M., S. L. Ishaug, and A. G. Mikos. Bone tissue engineering. Nat. Med. 1:1322-1324, 1995.

${ }^{20}$ Deschamps, A. A., M. B. Claase, W. J. Sleijster, J. D. de Bruijn, D. W. Grijpma, and J. Feijen. Design of segmented poly(ether ester) materials and structures for the tissue engineering of bone. J. Control. Release 78:175-186, 2002.

${ }^{21}$ Elisseeff, J., K. Anseth, D. Sims, W. McIntosh, M. Randolph, and R. Langer. Transdermal photopolymerization for minimally invasive implantation. Proc. Nat. Acad. Sci. U.S.A. 96:31043107, 1999.

${ }^{22}$ Elsdale, T., and J. Bard. Collagen substrata for studies on cell behavior. J. Cell Biol. 54:626-637, 1972.

${ }^{23}$ Ertel, S. I., and J. Kohn. Evaluation of a Series of TyrosineDerived Polycarbonates as Degradable Biomaterials. J. Biomed. Mater. Res. 28:919-930, 1994.

${ }^{24}$ Fialkov, J. A., C. E. Holy, M. S. Shoichet, and J. E. Davies. In vivo bone engineering in a rabbit femur. J. Craniofac. Surg. 14:324-332, 2003.

${ }^{25}$ Gao, J. M., L. Niklason, and R. Langer. Surface hydrolysis of poly(glycolic acid) meshes increases the seeding density of vascular smooth muscle cells. J. Biomed. Mater. Res. 42:417424, 1998.

${ }^{26}$ Giordano, R. A., B. M. Wu, S. W. Borland, L. G. Cima, E. M. Sachs, and M. J. Cima. Mechanical properties of dense polylactic acid structures fabricated by three dimensional printing. J. Biomater. Sci.-Polym. Ed. 8:63-75, 1996.

${ }^{27}$ Girton, T. S., V. H. Barocas, and R. T. Tranquillo. Confined compression of a tissue-equivalent: collagen fibril and cell alignment in response to anisotropic strain. J. Biomech. Eng. 124:568-575, 2002.
${ }^{28}$ Griffith, L. G. Emerging design principles in Biomaterials and scaffolds for tissue engineering. Ann. N.Y. Acad. Sci. 961:8395, 2002.

${ }^{29}$ Griffith, L. G., and G. Naughton. Tissue engineering-Current challenges and expanding opportunities. Science. 295:10091013, 2002.

${ }^{30}$ Grinnell, F., and M. H. Bennett. Ultrastructural studies of cellcollagen interactions. Methods Enzymol. 82:535-544, 1982.

${ }^{31}$ Han, D. K., and J. A. Hubbell. Lactide-based poly(ethylene glycol) polymer networks for scaffolds in tissue engineering. Macromolecules 29:5233-5235, 1996.

${ }^{32}$ Hanes, J., M. Chiba, and R. Langer. Degradation of porous poly(anhydride-co-imide) microspheres and implications for controlled macromolecule delivery. Biomaterials 19:163-172, 1998.

${ }^{33}$ Harris, L. D., B. S. Kim, and D. J. Mooney. Open pore biodegradable matrices formed with gas foaming. J. Biomed. Mater. Res. 42:396-402, 1998.

${ }^{34}$ Hench, L. L., and J. M. Polak. Third-generation biomedical materials. Science 295:1014-1017, 2002.

${ }^{35}$ Hollinger, J. Strategies for Regenerating Bone of the Craniofacial Complex. Bone 14:575-580, 1993.

${ }^{36}$ Hollinger, J. O., and G. C. Battistone. Biodegradable bone repair materials-Synthetic-polymers and ceramics. Clin. Orthop. Rel. Res. 290-305, 1986.

${ }^{37} \mathrm{Hu}$, Y. H., S. R. Winn, I. Krajbich, and J. O. Hollinger. Porous polymer scaffolds surface-modified with arginine- glycineaspartic acid enhance bone cell attachment and differentiation in vitro. J. Biomed. Mater. Res. Part A 64A:583-590, 2003.

${ }^{38}$ Huang, L., K. Nagapudi, R. P. Apkarian, and E. L. Chaikof. Engineered collagen-PEO nanofibers and fabrics. J. Biomater. Sci.-Polym. Ed. 12:979-993, 2001.

${ }^{39}$ Hutmacher, D. W. Scaffold design and fabrication technologies for engineering tissues - state of the art and future perspectives. J. Biomater. Sci.-Polym. Ed. 12:107-124, 2001.

${ }^{40}$ Hutmacher, D. W. Scaffolds in tissue engineering bone and cartilage. Biomaterials. 21:2529-2543, 2000.

${ }^{41} \mathrm{Ibim}, \mathrm{S}$. M., K. E. Uhrich, R. Bronson, S. F. El-Amin, R. S. Langer, and C. T. Laurencin. Poly(anhydride-co-imides): in vivo biocompatibility in a rat model. Biomaterials 19:941-951, 1998.

${ }^{42}$ Ishaug, S. L., G. M. Crane, M. J. Miller, A. W. Yasko, M. J. Yaszemski, and A. G. Mikos. Bone formation by three-dimensional stromal osteoblast culture in biodegradable polymer scaffolds. J. Biomed. Mater. Res. 36:17-28, 1997.

${ }^{43}$ Kadler, K. E., D. F. Holmes, J. A. Trotter, and J. A. Chapman. Collagen fibril formation. Biochem. J. 316:1-11, 1996.

${ }^{44}$ Karp, J. M., K. Rzeszutek, M. S. Shoichet, and J. E. Davies. Fabrication of precise cylindrical three-dimensional tissue engineering scaffolds for in vitro and in vivo bone engineering applications. J. Craniofac. Surg. 14:317-323, 2003.

${ }^{45}$ Kenley, R., L. Marden, T. Turek, L. Jin, E. Ron, and J. O. Hollinger. Osseous regeneration in the rat calvarium using novel delivery systems for recombinant human bone morphogenetic protein-2 (rhBMP-2). J. Biomed Mater. Res. 28:1139-1147, 1994.

${ }^{46}$ Kuberka, M., D. Von Heimburg, H. Schoof, I. Heschel, and G. Rau. Magnification of the pore size in biodegradable collagen sponges. Int. J. Artif. Organs. 25:67-73, 2002.

${ }^{47}$ Kuntz, R. M., and W. M. Saltzman. Neutrophil motility in extracellular matrix gels: Mesh size and adhesion affect speed of migration. Biophys. J. 72:1472-1480, 1997.

${ }^{48}$ Kuo, C. K., and P. X. Ma. lonically crosslinked alginate hydrogels as scaffolds for tissue engineering: 1 . Structure, gelation 
rate and mechanical properties. Biomaterials 22:511-521, 2001.

${ }^{49}$ Langer, R. Biomaterials: Status, challenges, and perspectives. AICHE J. 46:1286-1289, 2000.

${ }^{50}$ Langer, R., and J. P. Vacanti. Tissue engineering. Science 260:920-926, 1993.

${ }^{51}$ Laurencin, C. T., M. A. Attawia, H. E. Elgendy, and K. M. Herbert. Tissue engineered bone-regeneration using degradable polymers: The formation of mineralized matrices. Bone 19:S93-S99, 1996.

${ }^{52}$ Laurencin, C. T., S. F. ElAmin, S. E. Ibim, D. A. Willoughby, M. Attawia, H. R. Allcock, and A. A. Ambrosio. A highly porous 3-dimensional polyphosphazene polymer matrix for skeletal tissue regeneration. J. Biomed. Mater. Res. 30:133-138, 1996.

${ }^{53}$ Lee, K. Y., E. Alsberg, and D. J. Mooney. Degradable and injectable poly(aldehyde guluronate) hydrogels for bone tissue engineering. J. Biomed. Mater. Res. 56:228-233, 2001.

${ }^{54} \mathrm{Li}$, W. J., C. T. Laurencin, E. J. Caterson, R. S. Tuan, and F. K. Ko. Electrospun nanofibrous structure: A novel scaffold for tissue engineering. J. Biomed. Mater. Res. 60:613-621, 2002.

${ }^{55} \mathrm{Li}$, W. J., C. T. Laurencin, E. J. Caterson, R. S. Tuan, and F. K. Ko. Electrospun nanofibrous structure: a novel scaffold for tissue engineering. J. Biomed. Mater. Res. 60:613-621, 2002.

${ }^{56}$ Liao, C. J., C. F. Chen, J. H. Chen, S. F. Chiang, Y. J. Lin, and K. Y. Chang. Fabrication of porous biodegradable polymer scaffolds using a solvent merging/particulate leaching method. J. Biomed. Mater. Res. 59:676-681, 2002.

${ }^{57}$ Livingston, T., P. Ducheyne, and J. Garino. In vivo evaluation of a bioactive scaffold for bone tissue engineering. J. Biomed. Mat. Res. 62:1-13, 2002.

${ }^{58}$ Lo, H., S. Kadiyala, S. E. Guggino, and K. W. Leong. Poly(Llactic acid) foams with cell seeding and controlled-release capacity. J. Biomed. Mater. Res. 30:475-484, 1996.

${ }^{59}$ Lutolf, M. R., F. E. Weber, H. G. Schmoekel, J. C. Schense, T. Kohler, R. Muller, and J. A. Hubbell. Repair of bone defects using synthetic mimetics of collagenous extracellular matrices. Nat. Biotechnol. 21:513-518, 2003.

${ }^{60}$ Lysaght, M. J., and J. Reyes. The growth of tissue engineering. Tissue Eng. 7:485-493, 2001.

${ }^{61} \mathrm{Ma}$, P. X. Tissue engineering. In: Encyclopedia of Polymer Science and Technology, edited by J. I. Kroschwitz. Hoboken, NJ: Wiley, in press.

${ }^{62} \mathrm{Ma}$, P. X., and J. W. Choi. Biodegradable polymer scaffolds with well-defined interconnected spherical pore network. Tissue Eng. 7:23-33, 2001.

${ }^{63}$ Ma, P. X., and R. Langer. Degradation, structure and properties of fibrous nonwoven poly(glycolic acid) scaffols for tissue engineering. In: Polymers in Medicine and Pharmacy, edited by A. G. Mikos, K. W. Leong, M. L. Radomsky, J. A. Tamada, and M. J. Yaszemski. Pittsburgh, PA: MRS, 1995, pp. 99-104.

${ }^{64} \mathrm{Ma}$, P. X., and R. Langer. Fabrication of Biodegradable Polymer foams for cell transplantation and tissue engineering. In: Tissue Engineering Methods and Protocols, edited by M. Yarmush and J. Morgen. Totowa, NJ: Humana Press, 1998, pp. 47-56.

${ }^{65} \mathrm{Ma}$, P. X., and R. Y. Zhang. Microtubular architecture of biodegradable polymer scaffolds. J. Biomed. Mater. Res. 56:469-477, 2001.

${ }^{66} \mathrm{Ma}$, P. X., and R. Y. Zhang. Synthetic nano-scale fibrous extracellular matrix. J. Biomed. Mater. Res. 46:60-72, 1999.

${ }^{67}$ Ma, P. X., R. Y. Zhang, G. Z. Xiao, and R. Franceschi. Engineering new bone tissue in vitro on highly porous poly(alpha-hydroxyl acids)/hydroxyapatite composite scaffolds. J. Biomed. Mater. Res. 54:284-293, 2001.

${ }^{68}$ Maquet, V., and R. Jerome. Design of macroporous biodegradable polymer scaffolds for cell transplantation. Mater. Sci.
Forum 250:15-42, 1997.

${ }^{69}$ Marra, K. G., J. W. Szem, P. N. Kumta, P. A. DiMilla, and L. E. Weiss. In vitro analysis of biodegradable polymer blend/hydroxyapatite composites for bone tissue engineering. J. Biomed. Mater. Res. 47:324-335, 1999.

${ }^{70}$ Matthews, J. A., G. E. Wnek, D. G. Simpson, and G. L. Bowlin. Electrospinning of collagen nanofibers. Biomacromolecules 3:232-238, 2002.

${ }^{71}$ Mikos, A. G., M. D. Lyman, L. E. Freed, and R. Langer. Wetting of poly(L-lactic acid) and poly(DL-lactic-co-glycolic acid) foams for tissue culture. Biomaterials 15:55-58, 1994.

${ }^{72}$ Mikos, A. G., A. J. Thorsen, L. A. Czerwonka, Y. Bao, R. Langer, D. N. Winslow, and J. P. Vacanti. Preparation and characterization of Poly(L-lactic acid) foams. Polymer 35:1068-1077, 1994.

${ }^{73}$ Miyamoto, S., and K. Takaoka. Bone induction and bone repair by composites of bone morphogenetic protein and biodegradable synthetic-polymers. Ann. Chir. Gynaecol. 82:69-75, 1993.

${ }^{74}$ Mizuno, M., M. Shindo, D. Kobayashi, E. Tsuruga, A. Amemiya, and Y. Kuboki. Osteogenesis by bone marrow stromal cells maintained on type I collagen matrix gels in vivo. Bone 20:101-107, 1997.

${ }^{75}$ Mooney, D. J., D. F. Baldwin, N. P. Suh, L. P. Vacanti, and R. Langer. Novel approach to fabricate porous sponges of poly(D, L-lactic-co-glycolic acid) without the use of organic solvents. Biomaterials 17:1417-1422, 1996.

${ }^{76}$ Nam, Y. S., and T. G. Park. Porous biodegradable polymeric scaffolds prepared by thermally induced phase separation. $J$. Biomed. Mater. Res. 47:8-17, 1999.

${ }^{77}$ Neff, J. A., K. D. Caldwell, and P. A. Tresco. A novel method for surface modification to promote cell attachment to hydrophobic substrates. J. Biomed. Mater. Res. 40:511-519, 1998.

${ }^{78}$ Nitschke, M., G. Schmack, A. Janke, F. Simon, D. Pleul, and C. Werner. Low pressure plasma treatment of poly(3hydroxybutyrate): Toward tailored polymer surfaces for tissue engineering scaffolds. J. Biomed. Mater. Res. 59:632-638, 2002.

${ }^{79}$ Peter, S. J., M. J. Miller, A. W. Yasko, M. J. Yaszemski, and A. G. Mikos. Polymer concepts in tissue engineering. J. Biomed. Mater. Res. 43:422-427, 1998.

${ }^{80}$ Peter, S. J., M. J. Yaszemski, L. J. Suggs, R. G. Payne, R. Langer, W. C. Hayes, M. R. Unroe, L. B. Alemany, P. S. Engel, and A. G. Mikos. Characterization of partially saturated poly(propylene fumarate) for orthopaedic application. $J$. Biomater. Sci. Polym. Edn. 8:893-904, 1997.

${ }^{81}$ Prestwich, G. D., and H. Matthew. Hybrid, composite, and complex biomaterials. Ann. N.Y. Acad. Sci. 961:106-108, 2002.

${ }^{82}$ Puleo, D. A., L. A. Holleran, R. H. Doremus, and R. Bizios. Osteoblast Responses to Orthopedic Implant Materials Invitro. J. Biomed. Mater. Res. 25:711-723, 1991.

${ }^{83}$ Reneker, D. H., and I. Chun. Nanometre diameter fibres of polymer, produced by electrospinning. Nanotechnology 7:216-223, 1996.

${ }^{84}$ Sachs, E., M. Cima, P. Williams, D. Brancazio, and J. Cornie. 3-Dimensional printing - Rapid tooling and prototypes directly from a Cad model. J. Eng. Ind.-Trans. ASME. 114:481-488, 1992.

${ }^{85}$ Schmedlen, R. H., K. S. Masters, and J. L. West. Photocrosslinkable polyvinyl alcohol hydrogels that can be modified with cell adhesion peptides for use in tissue engineering. Biomaterials 23:4325-4332, 2002.

${ }^{86}$ Schoof, H., J. Apel, I. Heschel, and G. Rau. Control of pore structure and size in freeze-dried collagen sponges. J. Biomed. Mater. Res. 58:352-357, 2001. 
${ }^{87}$ Schugens, C., V. Maquet, C. Grandfils, R. Jerome, and P. Teyssie. Polylactide macroporous biodegradable implants for cell transplantation .2. Preparation of polylactide foams by liquid-liquid phase separation. J. Biomed. Mater. Res. 30:449-461, 1996.

${ }^{88}$ Shang, Q., Z. Wang, W. Liu, Y. Shi, L. Cui, and Y. Cao. Tissue-engineered bone repair of sheep cranial defects with autologous bone marrow stromal cells. J. Craniofac. Surg. 12:586-593, 2001

${ }^{89}$ Sikavitsas, V. I., G. N. Bancroft, and A. G. Mikos. Formation of three-dimensional cell/polymer constructs for bone tissue engineering in a spinner flask and a rotating wall vessel bioreactor. J. Biomed. Mat. Res. 62:136-148, 2002.

${ }^{90}$ Solchaga, L. A., J. E. Dennis, V. M. Goldberg, and A. I. Caplan. Hyaluronic acid-based polymers as cell carriers for tissue-engineered repair of bone and cartilage. J. Orthop. Res. 17:205-213, 1999.

${ }^{91}$ Tan, J., and W. M. Saltzman. Influence of synthetic polymers on neutrophil migration in three-dimensional collagen gels. $J$. Biomed. Mat. Res. 46:465-474, 1999.

${ }^{92}$ Thomson, R. C., M. C. Wake, M. J. Yaszemski, and A. G. Mikos. Biodegradable polymer scaffolds to regenerate organs. Adv. Polym. Sci. 122:245-274, 1995.

${ }^{93}$ Thomson, R. C., M. J. Yaszemski, J. M. Powers, and A. G. Mikos. Fabrication of Biodegradable Polymer Scaffolds to Engineer Trabecular Bone. J. Biomater. Sci.-Polym. Ed. 7:23-38, 1995.

${ }^{94}$ Thomson, R. C., M. J. Yaszemski, J. M. Powers, and A. G. Mikos. Hydroxyapatite fiber reinforced poly(alpha-hydroxy ester) foams for bone regeneration. Biomaterials 19:1935-1943, 1998.

${ }^{95}$ Uhrich, K. E., A. Gupta, T. T. Thomas, C. T. Laurencin, and R. Langer. Synthesis and characterization of degradable poly(anhydride-co-imides). Macromolecules 28:2184-2193, 1995.

${ }^{96}$ Vacanti, C. A., and J. P. Vacanti. Bone and cartilage reconstruction. In: Principles of Tissue Engineering, edited by R. P. Lanza, R. Langer, and W. L. Chick. Austin, TX: R. G. Landes Company, 1997, pp. 619-631.

${ }^{97}$ Vacanti, J. P., M. A. Morse, W. M. Saltzman, A. J. Domb, A. Perezatayde, R. Langer, C. L. mazzoni, and C. K. Breuer. Selective cell transplantation using bioabsorbable artificial polymers as matrices. J. Pediatr. Surg. 23:3-9, 1988.

${ }^{98}$ Wang, X., X. Li, R. A. Bank, and C. M. Agrawal. Effects of collagen unwinding and cleavage on the mechanical integrity of the collagen network in bone. Calcif. Tissue Int. 71:186-192, 2002.

${ }^{99}$ Webster, T. J., C. Ergun, R. H. Doremus, R. W. Siegel, and R. Bizios. Specific proteins mediate enhanced osteoblast adhesion on nanophase ceramics. J. Biomed. Mater. Res. 51:475-483, 2000.

${ }^{100}$ Wei, G., and P. X. Ma. Structure and properties of nanohydroxyapatite/polymer composite scaffolds for bone tissue engineering. Biomaterials, in press.

${ }^{101}$ Whang, K., C. H. Thomas, K. E. Healy, and G. Nuber. A novel method to fabricate bioabsorbable scaffolds. Polymer 36:837-842, 1995.

${ }^{102}$ Whang, K., D. C. Tsai, E. K. Nam, M. Aitken, S. M. Sprague, P. K. Patel, and K. E. Healy. Ectopic bone formation via rhBMP-2 delivery from porous bioabsorbable polymer scaffolds. J. Biomed. Mater. Res. 42:491-499, 1998.

${ }^{103}$ Woo, K. M., V. J. Chen, and P. X. Ma. Nano-fibrous scaffolding architecture selectively enhances protein adsorption contributing to cell attachment. J. Biomed. Mater. Res. A67:531-537, 2003.

${ }^{104}$ Yamamoto, M., K. Kato, and Y. Ikada. Ultrastructure of the interface between cultured osteoblasts and surface-modified polymer substrates. J. Biomed. Mater. Res. 37:29-36, 1997.

${ }^{105}$ Yang, S. F., K. F. Leong, Z. H. Du, and C. K. Chua. The design of scaffolds for use in tissue engineering. Part 1. Traditional factors. Tissue Eng. 7:679-689, 2001.

${ }^{106}$ Yang, S. F., K. F. Leong, Z. H. Du, and C. K. Chua. The design of scaffolds for use in tissue engineering. Part II. Rapid prototyping techniques. Tissue Eng. 8:1-11, 2002.

${ }^{107}$ Yaszemski, M. J., R. G. Payne, W. C. Hayes, R. Langer, T. B. Aufdemorte, and A. G. Mikos. The ingrowth of new bone tissue and initial mechanical properties of a degradable polymeric composite scaffold. Tissue Eng. 1:41-52, 1995.

${ }^{108}$ Yoshimoto, H., Y. M. Shin, H. Terai, and J. P. Vacanti. A biodegradable nanofiber scaffold by electrospinning and its potential for bone tissue engineering. Biomaterials 24:2077-2082, 2003.

${ }^{109}$ Zhang, R., and P. X. Ma. Processing of polymer scaffolds: Phase separation. In: Methods of Tissue Engineering, edited by A. Atala and R. Lanza. San Diego, CA: Academic Press, 2001, pp. 715-724.

${ }^{110}$ Zhang, R. Y., and P. X. Ma. Poly(alpha-hydroxyl acids) hydroxyapatite porous composites for bone-tissue engineering. I. Preparation and morphology. J. Biomed. Mater. Res. 44:446-455, 1999.

${ }^{111}$ Zhang, R. Y., and P. X. Ma. Porous poly(L-lactic acid)/apatite composites created by biomimetic process. J. Biomed. Mater. Res. 45:285-293, 1999.

${ }^{112}$ Zhang, R. Y., and P. X. Ma. Synthetic nano-fibrillar extracellular matrices with predesigned macroporous architectures. $J$. Biomed. Mater. Res. 52:430-438, 2000. 